This article was downloaded by: [Universiteit Twente]

On: 12 January 2009

Access details: Access Details: [subscription number 907217948]

Publisher Taylor \& Francis

Informa Ltd Registered in England and Wales Registered Number: 1072954 Registered office: Mortimer House, 37-41 Mortimer Street, London W1T 3JH, UK

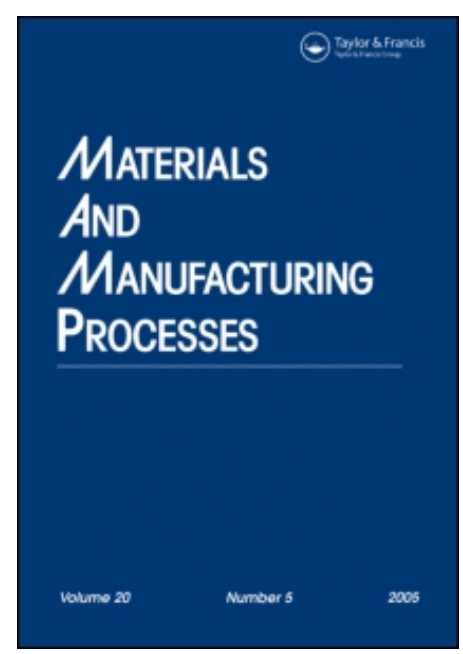

Materials and Manufacturing Processes

Publication details, including instructions for authors and subscription information:

http://www.informaworld.com/smpp/title content=t713597284

\title{
THIN ALUMINA AND SILICA FILMS BY CHEMICAL VAPOR DEPOSITION
} (CVD)

R. Hofrnan a; R. W. J. Morssinkhof a; T. Fransen a; J. G. F. Westheim a; P. J. Gellings a

a Department of Chemical Technology, Division of Corrosion Science and Inorganic Chemistry, University of

Twente, Enschede, AE, The Netherlands

Online Publication Date: 01 May 1993

To cite this Article Hofrnan, R., Morssinkhof, R. W. J., Fransen, T., Westheim, J. G. F. and Gellings, P. J.(1993)'THIN ALUMINA AND SILICA FILMS BY CHEMICAL VAPOR DEPOSITION (CVD)',Materials and Manufacturing Processes,8:3,315 - 329

To link to this Article: DOI: $10.1080 / 10426919308934836$

URL: http://dx.doi.org/10.1080/10426919308934836

\section{PLEASE SCROLL DOWN FOR ARTICLE}

Full terms and conditions of use: http://www.informaworld.com/terms-and-conditions-of-access.pdf

This article may be used for research, teaching and private study purposes. Any substantial or systematic reproduction, re-distribution, re-selling, loan or sub-licensing, systematic supply or distribution in any form to anyone is expressly forbidden.

The publisher does not give any warranty express or implied or make any representation that the contents will be complete or accurate or up to date. The accuracy of any instructions, formulae and drug doses should be independently verified with primary sources. The publisher shall not be liable for any loss, actions, claims, proceedings, demand or costs or damages whatsoever or howsoever caused arising directly or indirectly in connection with or arising out of the use of this material. 


\title{
THIN ALUMINA AND SILICA FILMS BY CHEMICAL VAPOR DEPOSITION (CVD)
}

\author{
R. Hofman, R.W.J. Morssinkhof, T. Fransen ${ }^{1}$, J.G.F. Westheim and P.J. Gellings \\ University of Twente, Department of Chemical Technology, Division of Corrosion \\ Science and Inorganic Chemistry, P.O. Box 217, 7500,4E Enschede \\ The Netherlands
}

\begin{abstract}
Alumina and silica coatings have been deposited by MOCVD (Metal Organic Chemical Vapor Deposition) on alloys to protect them against high temperature corrosion. Aluminium Tri-lsopropoxide (ATI) and DiAcetoxyDitertiaryButoxySilane (DADBS) have been used as metal organic precursors to prepare these ceramic coatings. The influence of several process steps on the deposition rate and surface morphology is discussed. The deposition of $\mathrm{SiO}_{2}$ at atmospheric pressure is kinetically limited below $833 \mathrm{~K}$ and is a mixed first and second order reaction with an activation energy of $155 \mathrm{~kJ}$.mole ${ }^{-1}$. The disposition of $\mathrm{Al}_{2} \mathrm{O}_{3}$ is kinetically limited below $673 \mathrm{~K}$ and is a first order reaction with an avitivation energy of 30 kJ.mole ${ }^{\cdot 1}$ at atmospheric pressure. The deposition of $\mathrm{Al}_{2} \mathrm{O}_{3}$ is kineticially limited below 623 $K$ and is a second order reaction at low pressure ( 3 torr) with an activation energy of 30 $\mathrm{kJ}$.mole ${ }^{-1}$. The decomposition of both precursors involves a B-hydrogen elimination reaction by which DADBS decomposes to acetic acid anhydride, 2-methyl prcipene, $\mathrm{SiO}_{2}$ and $\mathrm{H}_{2} \mathrm{O}$, while ATI decomposes to 2-propanol, propene, $\mathrm{Al}_{2} \mathrm{O}_{3}$ and $\mathrm{H}_{2} \mathrm{O}$.
\end{abstract}

\section{INTRODUCTION}

The interest in ceramic coatings has recently increased. These coatings are used to increase wear and corrosion resistance of base materials, but are mostly used for optical and electrical device fabrication. In the last two fields, where highly pure coatings are required, CVD has become a very popular coating technique and an enormous number of papers has been published concerning the characterization of these coatings. The number of papers concerned with the CVD process itself is far less, although some good reviews are available $(1,2,3)$. Van Frekel $(1)$ introduced a model to explain the deposition rate and the surface morphology as a function of the

${ }^{1}$ To whom all correspondence should be addressed. 
reaction temperature. This model is based on chemical reactions and transport of reactants and products and nowadays still the base of all other models describing CVD processes.

Next to the best known Atmospheric Pressure (APCVD) and Low Pressure Chemical Vapor Deposition (LPCVD) techniques, modified CVD-techniques have been used. These techniques have other activation sources to start the chemical reaction of the precursors than thermal heating. The substrate temperature will then be lowered and unwanted side reactions of the substrate are avoided. Examples of these techniques are Plasma Enhanced (PECVD), Laser (LCVD), Electron Beam (EBCVD) and Microwave (MCVD) Chemical Vapor Deposition. Metal Organic Chemical Vapor Deposition (MOCVD) has also been used to reduce the deposition temperature. This technique is based on the fact that metal organic precursors are highly instable and therefore coatings are formed at reasonably low temperatures.

In this work the synthesis of alumina and silica films by MOCVD is described. The processing of MOCVD coatings is almost identical to that of APCVD and LPCVD coatings. Gas phase reactions preliminary to the deposition reaction have been included in this model. The models used in this work can be applied to APCVD, LPCVD and MOCVD. The protective properties of the coatings are not considered here, but published elsewhere $(4,5)$.

\section{$\underline{\text { THEORY }}$}

The study of the CVD process is based on thermodynamics and kinetics. Thermodynamic studies give information on whether the precursors react to the desired coating, while kinetic studies give information about the deposition rate. Thermodynamic calculations have mostly been performed with computer programs like SOLGASMIX (6), but are hardly possible for MOCVD processes, due to a lack of thermodynamic data of MO-compounds. Furthermore it should be pointed out that kinetic theories, concerning MOCVD, are always based on curve fitting instead of on modelling of molecular processes, because the number of possible reaction steps is very large.

Most MOCVD processes have been performed in a plug flow reactor. In this type of reactor the MOCVD process can be divided in several process steps involving transport and reaction (Fig.1):

- Supply of evaporated reactant(s) by an inert gas stream

- Gas phase reactions

- Diffusion of reactants or intermediates from the gas through a stagnant boundary layer to the surface

- Adsorption of the reactants or intermediates on the surface

- Chemical reactions on the surface, resulting in the desired product layer and some by-products

- Desorption of by-products 


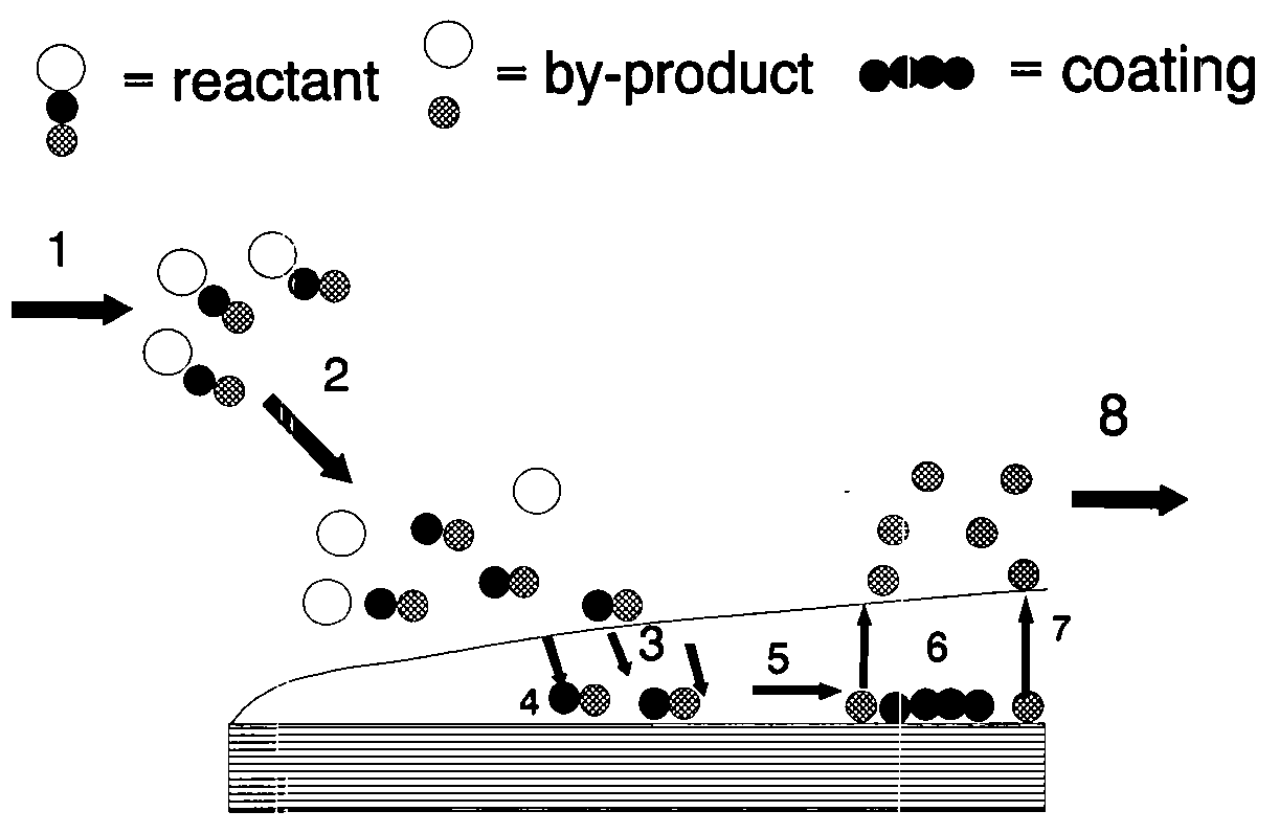

Figure 1. Schematic model of the CVD process (see text)
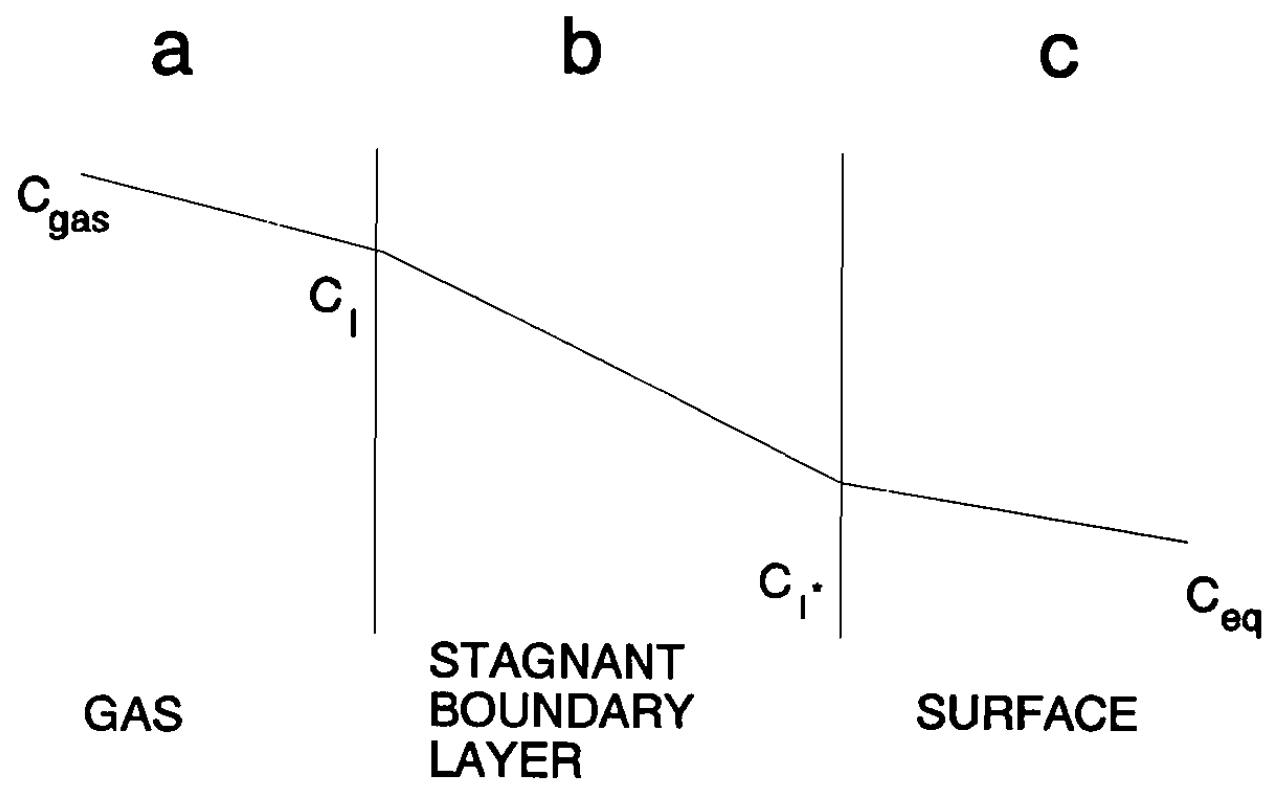

Figure 2. Schematic representation of the stagnant boundary layer model, in which gas phase (region a) and surface reactions (region c) and diffusion through the stagnant boundary layer (region b) occur. 
- Diffusion of by-products from the surface through the stagnant boundary layer to the gas phase

- Removal of by-products and unreacted species

The slowest step in this reaction sequence determines not only the overall reaction (= deposition) rate, but it can also influence the surface morphology. From this fact, it can be concluded that knowledge about every step is necessary to produce a coating with the desired properties.

Steps 1 and 8 can easily be manipulated by adjusting the total flux and are therefore not assumed to be rate limiting. In the first part of this section, the diffusion across the stagnant boundary layer and the chemical reactions are discussed, while rate limitation by ad/desorption reactions is discussed in the last part of this section.

When reaction and/or diffusion processes are considered to be rate limiting, three concentration gradients can be observed: one in the gas phase (caused by gas phase reactions), one across the stagnant boundary layer (due to the diffusion processes) and one on the surface (due to surface reactions) (Fig.2). An accumulation of species will be caused by the slowest process and the concentration gradient caused by that process will be larger than all others.

The diffusion flux can be calculated from Fick's first law:

$$
J_{B . L}=\frac{D}{\delta}\left(c_{1}-c_{1}\right)
$$

The chemical reaction rates in the gas phase (2a) and on the substrate (2b) can be described by:

$$
\begin{gathered}
r_{g a}-k_{1}\left(c_{R}-c_{1}\right)^{n} \\
r_{1}-k_{2}\left(c_{l^{*}}-c_{e q}\right)^{m}
\end{gathered}
$$

When both reactions are assumed to be first order in $c_{R}$ and $c_{i=}$, the combination of equation (1) and (2) leads to:

$$
\begin{aligned}
& \frac{c_{R}-c_{1}}{c_{I}-c_{l^{*}}}-\frac{D}{k_{1} \delta}-\frac{1}{S h_{1}} \\
& \frac{c_{1^{*}}-c_{e q}}{c_{1}-c_{l^{*}}}-\frac{D}{k_{2} \delta}-\frac{1}{S h_{2}}
\end{aligned}
$$

In this equation $(k \delta) / D$ is the dimensionless $S h(e r w o o d)$ number. From these equations two limiting situations can be recognized: 
1. If $\mathrm{Sh}<<1$, the concentration gradient across the stagnant boundary layer is almost zero, i.e., the growth rate is limited by the chemical reaction.

2. If Sh $>1$, the concentration gradient across the stagnant boundary layer is larger than the other gradients and the growth rate is limited by the diffusion through this layer.

(MO)CVD processes are reaction limited at low temperatures, and at higher temperatures the diffusion is rate limiting (1) (Fig.3). Coatings produced under diffusion limiting conditions have an inhomogeneous layer thickness, due to the fact that the thickness of the stagnant boundary layer is a function of the flow pattern around the substrate and its surface condition. Coatings, formed under the reaction limiting condition, have a uniform coating thickness (5).

In the reaction limited regime, gas phase (left part equation 4) or surface reactions (right part equation 4 ) can be rate limiting:

$$
\mathrm{R} \stackrel{\mathrm{k}_{1}}{\rightarrow} \mathrm{I} \stackrel{k_{2}}{\rightarrow} \mathrm{P}
$$

The consumption rate of the reactants can be given by:

$$
\phi \frac{\partial C_{R}}{\partial x}--k_{1} \cdot C_{R}
$$

The reaction rate of the intermediate is given by:

$$
\phi \frac{\partial C_{1}}{\partial x}=-k_{2} C_{1}+k_{1} C_{R}
$$

While the rate of product formation is given by:

$$
\phi \frac{\partial C_{P}}{\partial x}-k_{2} C_{I}
$$

In these equations, influences of thermal gradients and transport in the reactor by diffusion are neglected, while the reactions are assumed to be first order. The reactant, intermediate, and product concentration and the position in the reactor are normalised, i.e., $C_{R}=c_{R} / c_{R 0}, C_{1}=c_{1} / c_{R 0}$ and $C_{p}=c_{P} / c_{R 0}\left(C_{A}+C_{I}+C_{P}=1\right)$ and $x=1 / l_{0}$. In Fig.4, the calculated concentration gradient profiles of the intermediate are given for different $k_{1} / k_{2}$ ratios. When $k_{1}$ is large compared to $k_{2}$ the intermediate formation can be neglected.

At concentrations above a critical value the adsorption and desorption rates of reactants and by-products become rate limiting, i.e., the surface becomes covered with 


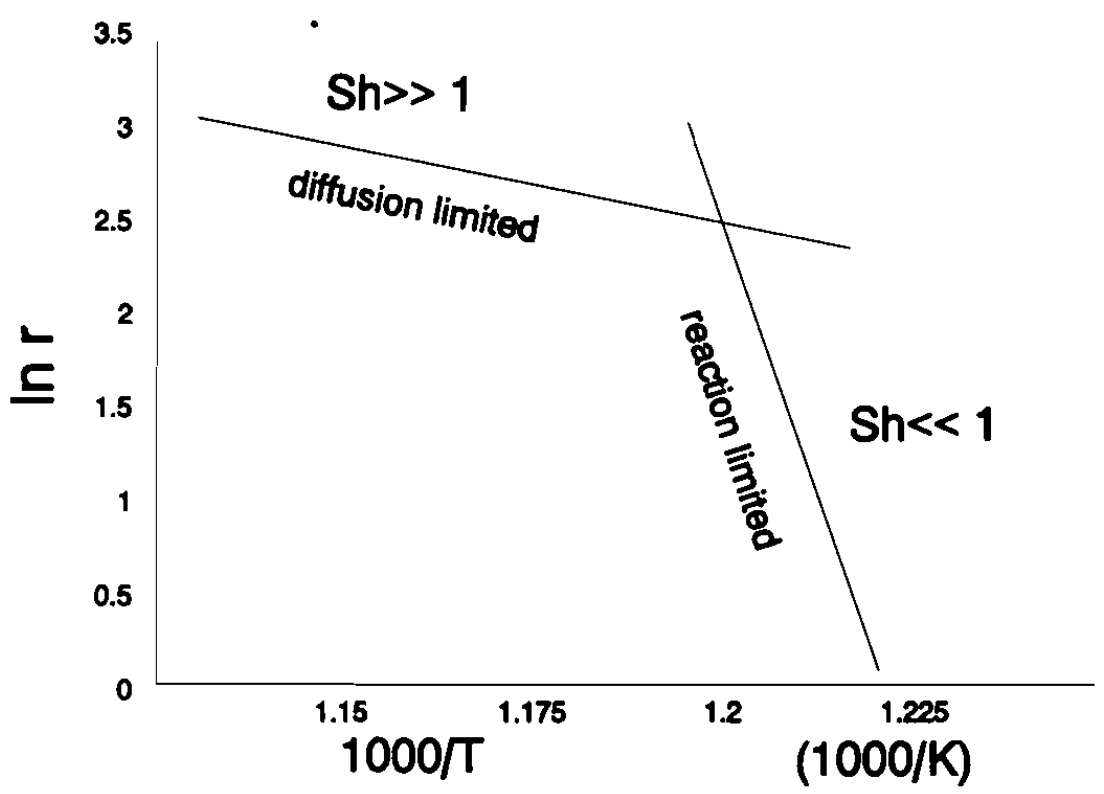

Figure 3. A theoretical Arrhenius plot of a CVD process in which diffusion (at high temperatures) and chemical reactions (at low temperatures) are rate limiting.

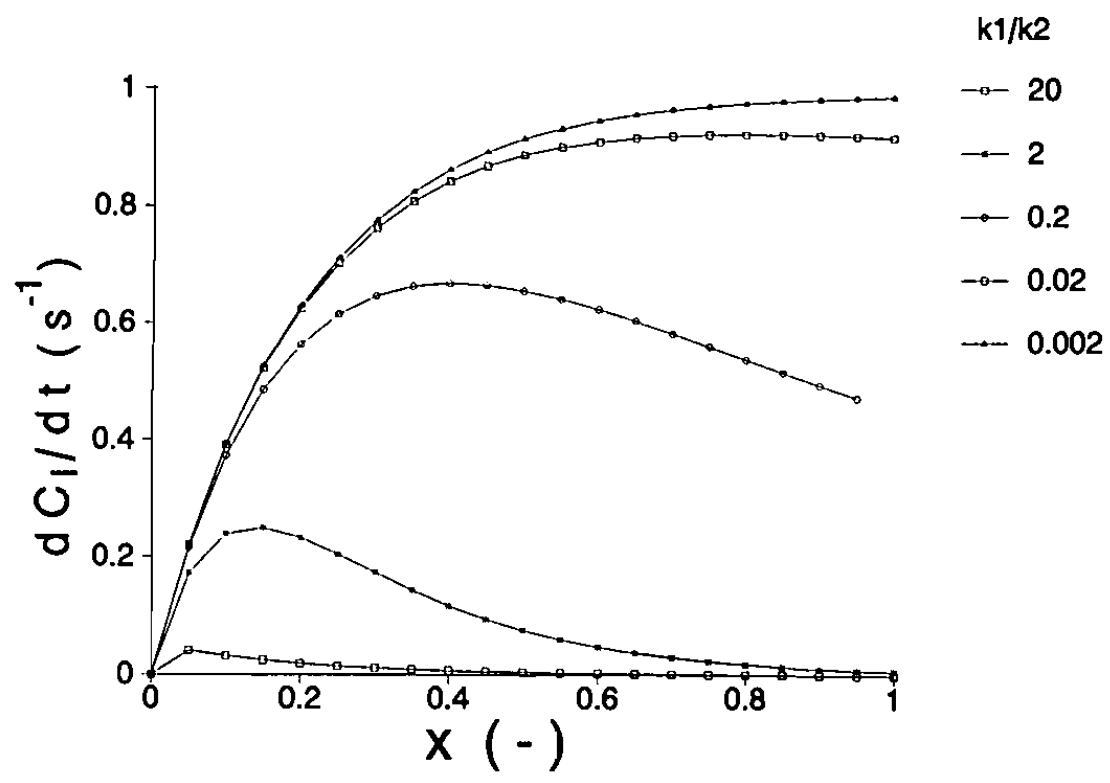

Figure 4. Theoretical profile of intermediate species in a tube furnace for different k-ratios for two serial first order reactions. 
those species. The rates of adsorption and desorption are, according to Langmuir, given by:

$$
\begin{gathered}
r_{\text {ads }}-k_{\text {ads }} c_{1}(1-\Theta) \\
r_{\text {des }}-k_{\text {des }} \cdot \Theta
\end{gathered}
$$

When these reactions are in equilibrium the surface coverage $(\Theta)$ can be calculated by:

$$
\Theta-\left[I_{s}\right]-\frac{\text { b.c. }}{\text { b.c. } c_{1}+1}
$$

This relation, in which the adsorption constant $b=k_{\mathrm{ads}} / k_{\text {des }}$, can be combined with the rate equation of the surface reaction:

$$
r_{\text {dep }}-k_{\text {dep }}\left[I_{s}\right]-\frac{k_{\text {dep }} \text { b.c. }}{b . c_{1}+1}
$$

As can be seen from Fig.5, the reaction rate in the high concentration regime becomes constant $\left(r_{\text {dep }}=k_{\text {dep }}\right)$.

\section{EXPERIMENTAL}

The MOCVD experiments were carried out either in a reactor at atmospheric pressure (Fig.6) or in a low pressure reactor (Fig.7). The Metal Organic precursors Aliminium Tri Isopropoxide (ATI) to produce $\mathrm{Al}_{2} \mathrm{O}_{3}$ coatings and DiAcetoxy Ditertairy-ButoxideSilane (DADBS) to produce $\mathrm{SiO}_{2}$ coatings are partially evaporated in a saturator vessel, which is kept at a constant temperature by an oil bath. A nitrogen gas stream (carrier gas) is passed through the saturator to transport the vapor to the reactor. Before the vapor stream enters the reactor it can be mixed with an extra amount of nitrogen gas (diluting gas) to reduce the vapor concentration. The furnace temperature is controlled by thermocouples which are placed inside the reaction tube. Unless stated otherwise, the temperature of the oil bath, the reactor pressure, the furnace temperature, and the flows of the diluting and carrier gas were kept constant during the experiments as given in Table 1.

Incoloy $800 \mathrm{H}$ was used as substrate during deposition experiments. Prior to deposition this alloy has been polished on $25,6,1$ and $0.25 \mu \mathrm{m}$ diamond paste and etched in a 5\% 3M $\mathrm{HNO}_{3} / 95 \%$ ethanol (P.A.) solution. The products of the decomposition reactions were monitored by a Mass spectrometer (SpectraMass) to obtain information about the decomposition chemistry of DADBS and ATI. 


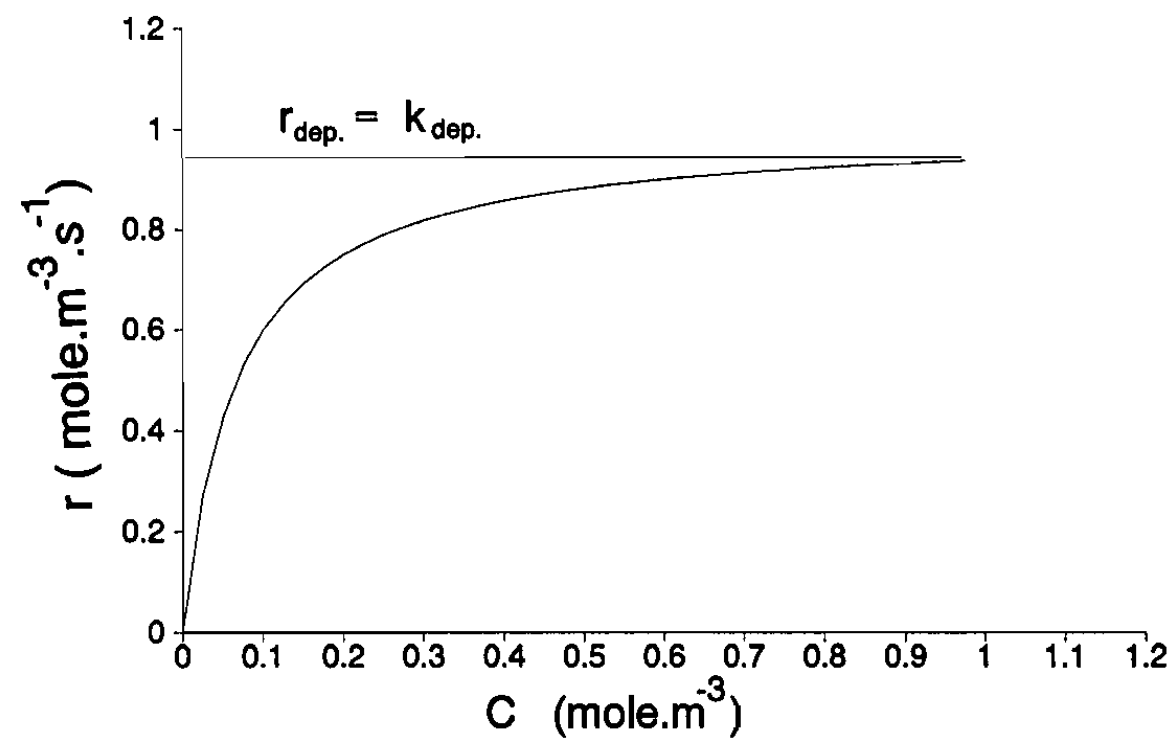

Figure 5. The reaction rate according to Langmuir model. At low concentrations a normal first order relation is observed, while at higher concentration the reaction rate becomes constant due to surface limitation.

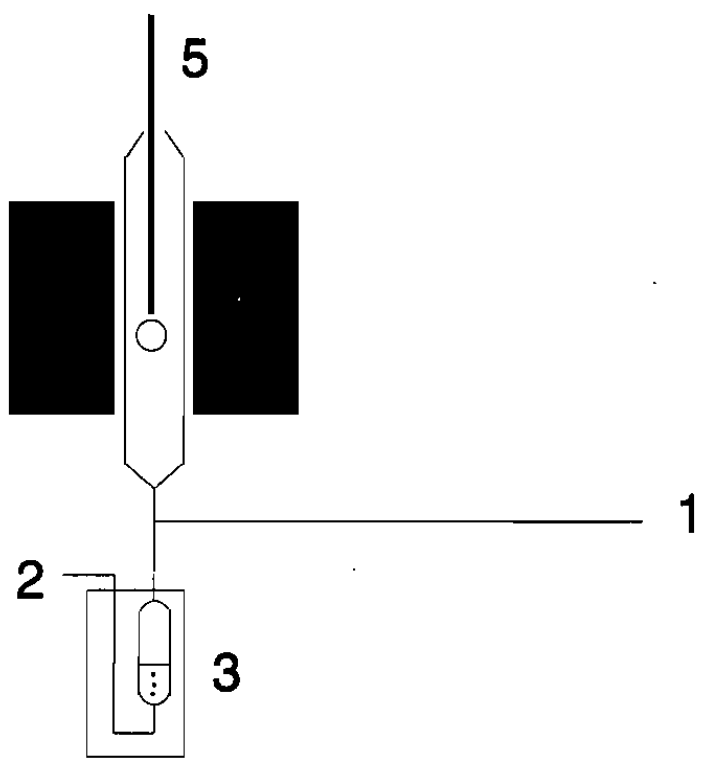

Figure 6. Schematic drawing of the atmospheric MOCVD-equipment. (1) nitrogen diluting gas, (2) nitrogen carrier gas, (3) evaporation vessel at constant temperature with metal organic precursor, (4) furnace, and (5) thermocouple with specimen. 


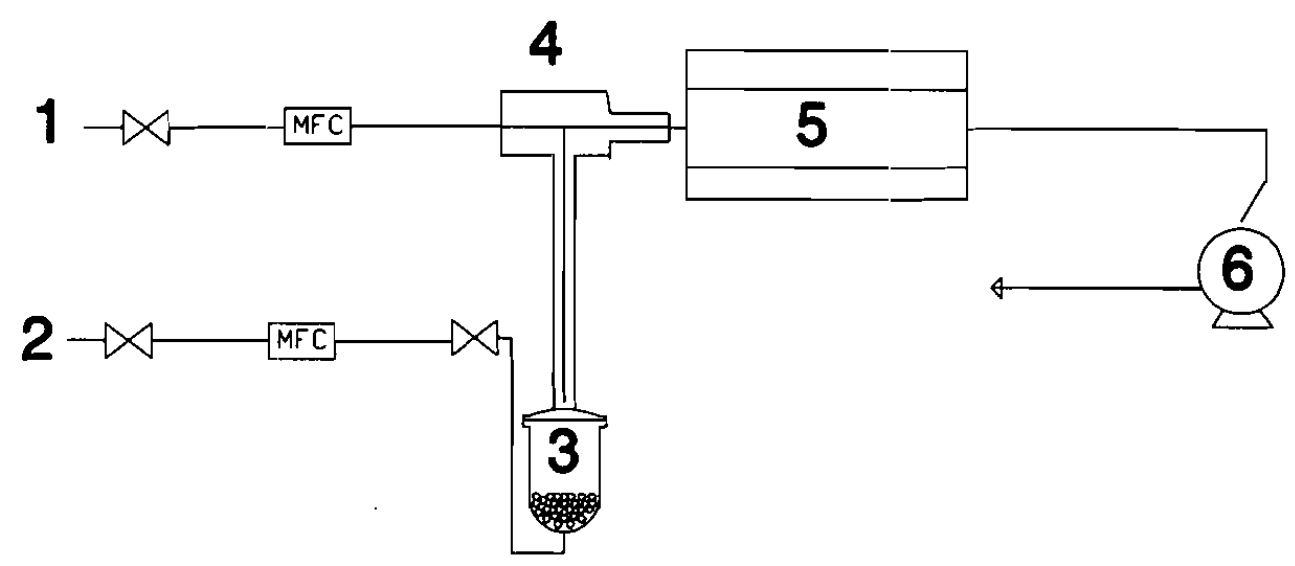

Figure 7. Schematic drawing of the low-pressure MOCVD-equipment. (1) nitrogen diluting gas, (2) nitrogen carrier gas, (3) evaporation vessel at constant temperature with metal organic precursor, (4) mixing chamber, (5) 3-zone furnace, and (6) vacuum pump.
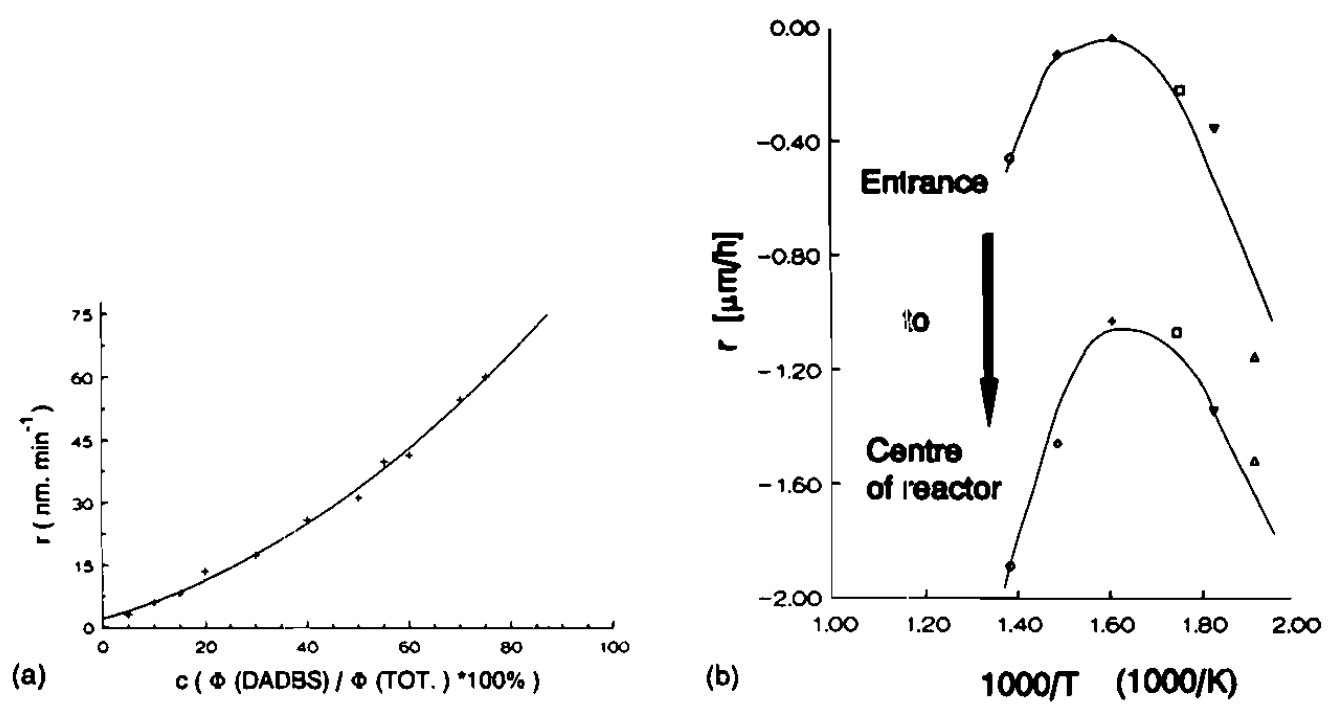

Figure 8. Measured Arrhenius plots of the deposition rate of $\mathrm{SiO}_{2}$ from DADBS (a) and $\mathrm{Al}_{2} \mathrm{O}_{3}$ from $\mathrm{ATT}(\mathrm{b})$. 


\section{RESULTS AND DISCUSSION}

\section{Determination of the Kinetic Regimes}

The analysis of the MOCVD process starts with the determination of the diffusion and reaction limited regimes, since for most applications only films with a uniform thickness can be used, and therefore the MOCVD process must be operated under reaction limited conditions. For both $\mathrm{Al}_{2} \mathrm{O}_{3}$ deposition from $\mathrm{ATI}$ and $\mathrm{SiO}_{2}$ from DADBS, Arrhenius plots were determined (Fig.8). The deposition of $\mathrm{SiO}_{2}$ with DADBS as a precursor is in agreement with the above described theory. From the reaction limited regime the activation energy of the chemical reaction is determined to be $150 \mathrm{~kJ} \cdot \mathrm{mole}^{-1}$. The optimum deposition temperature (= highest reaction rate in reaction limited regime) for the $\mathrm{SiO}_{2}$-process is about $833 \mathrm{~K}$. The results of ATI are more complicated, since the reaction rate at the highest temperatures decreases, which can be explained by the fact that the intermediate concentration decreases by gas phase polymerisation (= powder formation). The activation energy for the decomposition reaction of ATI is $30 \mathrm{~kJ}^{\mathrm{mole}}{ }^{-1}$. The decomposition of ATI is kinetically limited below $673 \mathrm{~K}$ at atmospheric pressure and below $623 \mathrm{~K}$ at low pressure ( 3 torr).

\section{Determination of the Reaction Order}

Once the reaction limited regime is determined, the chemical reaction rate at constant temperature can be optimised by changing the concentration of the MOcompound in the gas stream. In general, the rate of each chemical reaction at a constant temperature is given by:

$$
\mathbf{r}-\mathbf{k} \cdot \mathbf{c}^{\mathrm{n}}
$$

For an accurate prediction of the reaction rate for each concentration the reaction order $\mathbf{n}$ is important. This order is often determined by using a double logarithmic plot of the reaction rate versus reactant concentration:

$$
\ln r-\ln k+n \cdot \ln c
$$

As can be seen from Fig.9, the $\mathrm{SiO}_{2}$-deposition rate has an increasing reaction order from 1 in the low concentration area to 1.6 in the high concentration area. This phenomenon may be explained by assuming that two different parallel reactions, one first order and one second order gas phase reaction are rate limiting (7).

$$
r_{\text {DADBS }}=k_{1} c_{D A D B S}+k_{2} c_{D A D B S}^{2}
$$

This polynomial model describes the measured data indeed very accurately, as seen in Fig.10A. The ad/desorption limitation (equation 11) of the $\mathrm{SiO}_{2}-\mathrm{MOCVD}$ process was not observed; the reaction rate at such high concentrations could not be 


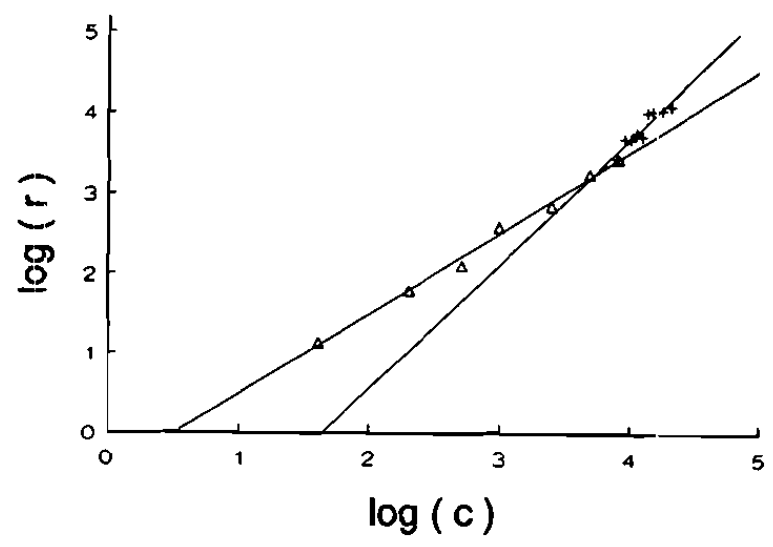

Figure 9. Order determination for the deposition rate of $\mathrm{SiO}_{2}$ from DADBS by a double logarithmic plot of the reaction rate $(r)$ versus the concentration (c).
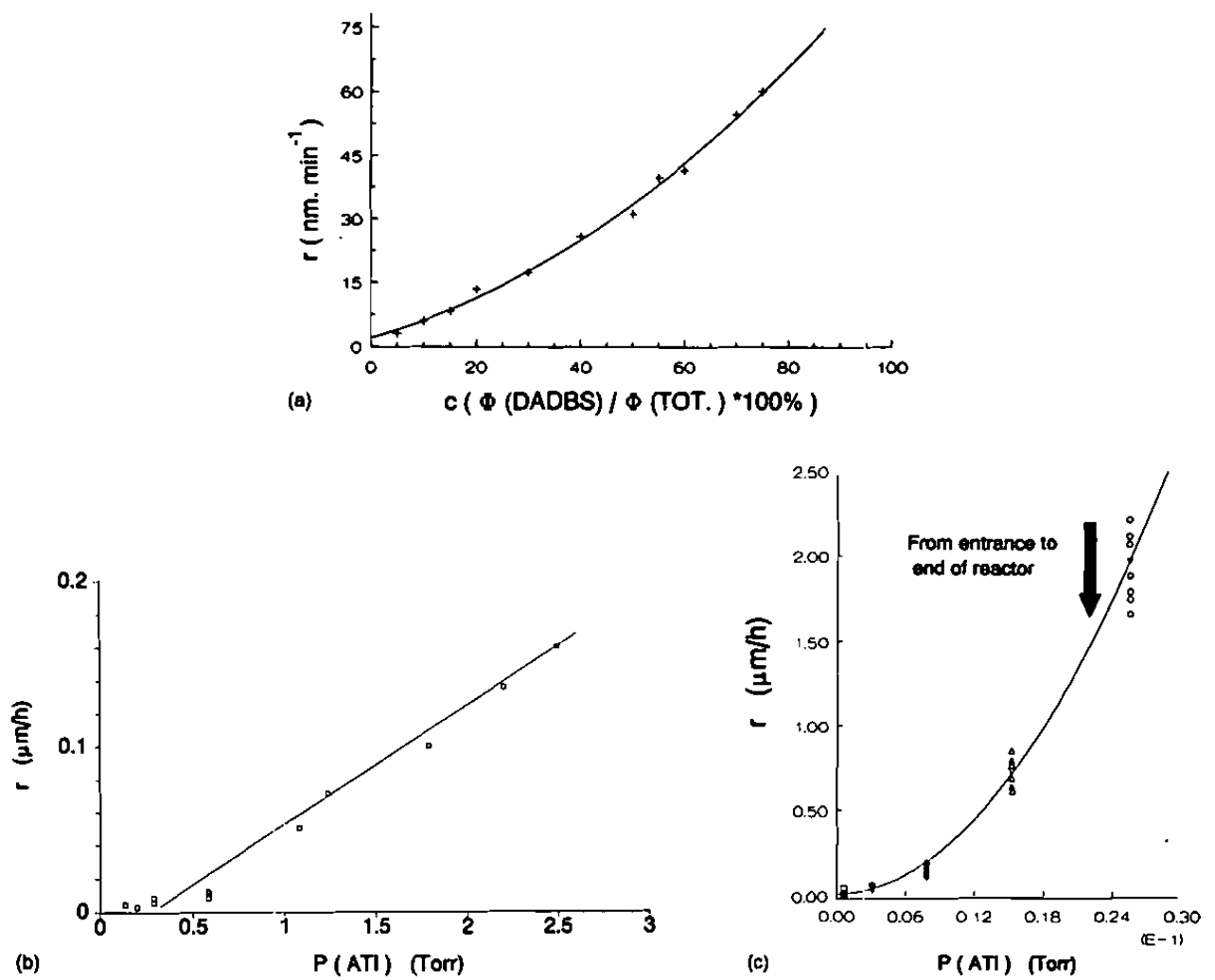

Figure 10. Measured and fitted reaction rates of $\mathrm{SiO}_{2}$ deposition at atmospheric pressure (a), of $\mathrm{Al}_{2} \mathrm{O}_{3}$ at atmospheric (b) and at low pressure (3 torr) (c) as a function of the precursor concentration in the vapor. 
determined due to spallation of the coatings within a few minutes, which leads to unacceptable errors in those data.

The deposition of ATI is a first order process at atmospheric pressure (Fig.10B) and a second order process at low pressure ( 3 torr) (Fig.10C). This can be explained when the dehydration reaction of $\mathrm{AlOOH}$ is rate limiting (8).

$$
2 \mathrm{O}-\mathrm{Al}-\mathrm{OH} \rightarrow \mathrm{Al}_{2} \mathrm{O}_{3}+\mathrm{H}_{2} \mathrm{O}
$$

This reaction explains the second order at low pressures, while the first eorder at atmospheric pressure can be explained by a combination of this reaction with the Langmuir adsorption model.

\section{The Reaction Rate as Function of the Position in the Furnace}

In Fig.11 the reaction rate of the $\mathrm{Al}_{2} \mathrm{O}_{3}$-formation is given as a function of the position in the low pressure furnace. The reaction rate decreases from the inlet (position 0) to the outlet of the furnace (position 9). The decreasing reaction rate is explained by the fact that intermediate formation is fast compared with the consumption rate of intermediates. This is in agreement with the above mentioned model for the $\mathrm{Al}_{2} \mathrm{O}_{3}$ deposition.

\section{The Decomposition Chemistry}

The lack of thermodynamic data implies that products formed during MOCVD processes can not be predicted, and therefore the decomposition chemistry of metal organic compounds has to be monitored. Knowledge about the decomposition chemistry could lead to an improved precursor selection and a better layer quality by changing the reaction path.

Mass spectroscopic experiments as a function of the reaction temperature (Fig.12) indicate that decomposition of the MO-compounds involves three steps. In the first two steps, organic groups are formed and in the third step $\mathrm{SiO}_{2}$ and $\mathrm{Al}_{2} \mathrm{O}_{3}$ are formed by polycondensation of the remaining acids. The products formed during decomposition of ATI are one propene and one 2-propanol (isopropanol) molecule in the first step and one propene group in the second step. In the first decomposition step of DADBS acetic acid anhydride is formed while in the second step 2-methyl propene is formed.

More theoretical work on the decomposition mechanism has been published elsewhere $(7,8)$. The most important point of this mechanism is the formation of a rather stable 6-ring by bridging of the $\beta$-hydrogen atom with an oxygen atom of another group of the same molecule (intra molecular reaction). Charge redistribution in this ring will be possible and the weakest bonds in this ring will be broken by releasing the mentioned organic groups. 


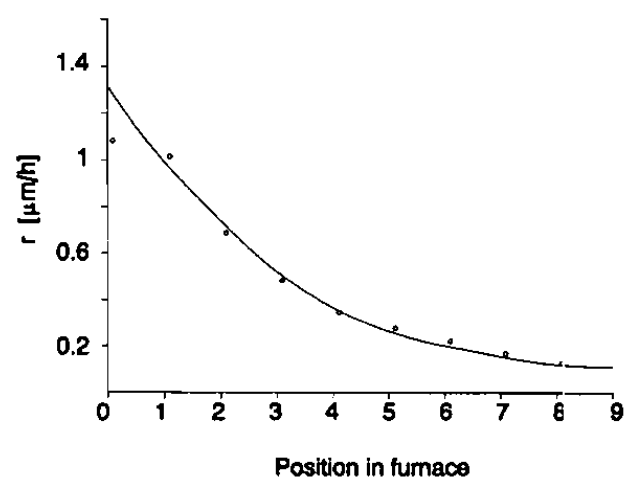

Figure 11. The deposition rate of $\mathrm{Al}_{2} \mathrm{O}_{3}$ at low pressure (3 torr) as a function of the position in the furnace $(0=$ entrance, $9==$ outlet $)$.
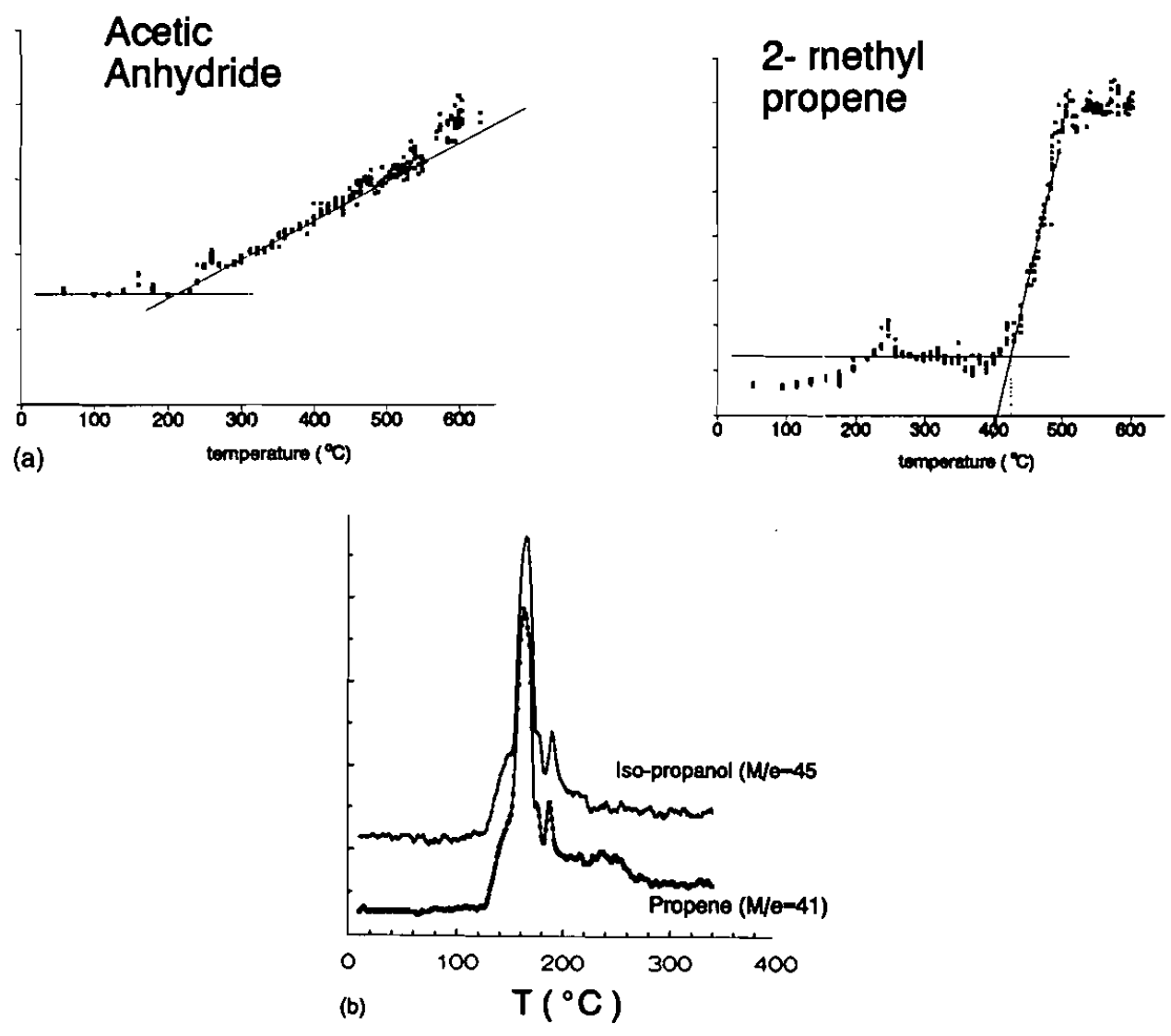

Figure 12. Vapor pressures of reaction products of the decomposition of DADBS (a) and ATI (b) measured by Mass Spectroscopy. 


\section{CONCLUSIONS}

Alumina and silica coatings have been deposited on Incoloy $800 \mathrm{H}$ by MOCVD. The influence of the reaction temperature and the partial pressure of the reactants have been studied. Both the decomposition of $\mathrm{DADBS}$ to $\mathrm{SiO}_{2}$ and the decomposition of $\mathrm{ATI}$ to $\mathrm{Al}_{2} \mathrm{O}_{3}$ can be described by a model in which transport to and from the substrate and reactions on the substrate and in the gas phase take place. The deposition of $\mathrm{SiO}_{2}$ is a combined first and second order reaction with an activation energy of $150 \mathrm{~kJ}^{\mathrm{mole}}{ }^{-1}$. This is explained by two parallel, one second and one first order, gas phase reactions. The deposition of $\mathrm{Al}_{2} \mathrm{O}_{3}$ is a first order reaction at atmospheric pressures while at low pressure (3 torr) it is a second order. Both reactions have an activation energy of $30 \mathrm{~kJ} \cdot \mathrm{mole}^{-1}$. This can be explained by a combination of a second order $\mathrm{AlOOH}$ dehydration reaction and a Langmuir adsorption model. The decomposition reaction of both DADBS and ATI involve a B-hydrogen elimination reaction. DADBS decomposes to acetic acid anhydride, 2methyl propene, $\mathrm{SiO}_{2}$ and $\mathrm{H}_{2} \mathrm{O}$, while ATI decomposes to 2-propanol, propene, $\mathrm{Al}_{2} \mathrm{O}_{3}$ and $\mathrm{H}_{2} \mathrm{O}$.

\section{$\underline{\text { LIST OF SYMBOLS }}$}

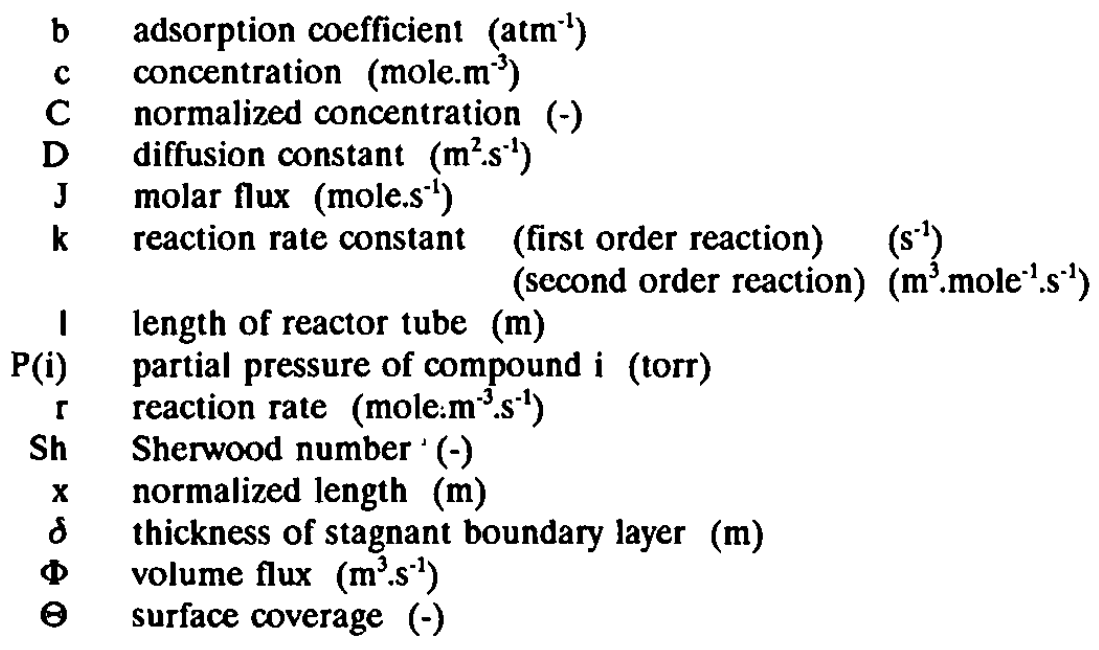

\section{$\underline{\text { INDICES }}$}

$\begin{aligned} \text { ads } & \text { adsorption } \\ \text { B.L. } & \text { boundary layer } \\ \text { des } & \text { desorption } \\ \text { gas } & \text { gas phase } \\ \text { I } & \text { intermediate in the gas phase } \\ I^{*} & \text { intermediate on the surface } \\ \text { m } & \text { reaction order constant }\end{aligned}$




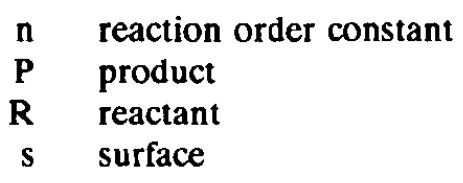

\section{ACKNOWLEDGEMENTS}

The Technology Foundation (STW) supported this research. The authors like to acknowledge dr. ir. V.T. Zaspalis for providing analysis facilities (Mass spectrometer).

\section{REFERENCES}

1. van den Brekel, C.H.J., Philips Research Reports, Vol.32, p.118, (1977).

2. Hitchmann, M.L., Progress in Crystal Growth and Characterisation, Vol.4, p.283, (1981).

3. Spear, K.E., Journal of Applied Chemistry, Vol.54, p.1297, (1985).

4. Hofman, R., J.G.F. Westheim, T. Fransen, and P.J. Gellings, in Surface Modification Technologies V, edited by T.S. Sudarshan and J.F.Braza, The Institute of Metals, London, 1992.

5. Morssinkhof, R.W.J., T. Fransen, M.M.D. Heusinkveld and P.J. Gellings, Materials Science and Technology, Vol.A121, p.449, (19:39).

6. Erikson, G., Chemica Scripta, Vol.8, p.100, (1975).

7. Hofman, R., J.G.F. Westheim, T. Fransen and P.J. Gellings, to be published.

8. Morssinkhof, R.W.J., The Deposition of Thin Alumina Films on Steels by MOCVD, PhD-thesis, University of Twente, 1991. 